DOI: $10.32743 /$ dictum-factum.2020.192-200

\title{
The System of Training Qualified Russian Translators / Interpreters in China: Problems and Prospects
}

\author{
Simin ZHAO \\ Postgraduate Student \\ Department of Russian Language and Literature \\ Institute for Russian, East European, and Central Asian Studies \\ Shanghai International Studies University \\ 1550, Wenxiang Road, Shanghai, 201620, China \\ +86 166-2152-5335 \\ 251053385@qq.com
}

\begin{abstract}
The article discusses the system of training qualified translators / interpreters working with the Russian-Chinese language pair in China. The purpose of the article is to consider the organizational and content aspects of the translator / interpreter training system. The sources of the material were the official websites of Chinese universities, testing system bodies, The Association of Chinese Translators / Interpreters and the results of surveys conducted by scholars. The article presents a characteristic of the following problems: a lack of translation / interpretation training focused on the work in a specific subject area; a lack of linking between bachelor's and master's degrees programmes; an insufficient intensity of international scientific exchange and a limited admission to the participation in translation / interpretation competitions. The article also suggests several ways of solving the identified problems. The results obtained in the article can be useful in the practice of training translators / interpreters, in developing curricula for students, in organizing translation / interpretation competitions, as well as for acquainting foreign scholars with the system of training translators / interpreters in China.
\end{abstract}

Keywords: system of training translators / interpreters; Russian language; Chinese universities; curriculum; testing and reward system. 


\section{Introduction}

In recent years there has been a strengthening of Russian-Chinese relations. The cooperation between the two countries is developing in political, economic, scientific, educational and other fields. In this regard, there is an increasing need for establishing interlanguage communication, and, consequently, a large number of qualified translators / interpreters with a Chinese-Russian language pair.

Every year the number of universities where Russian is taught is increasing in China. Currently, there are 152 such universities. Professional training of translators / interpreters is mainly carried out in the Higher Schools of Translation at specialized linguistic universities, as well as within the master's degree programmes at language departments of multidisciplinary universities. At the same time, at most universities within the framework of the bachelor's degree programmes students study in the specialty "Russian language" where classes in translation and interpretation are included in the curriculum only in senior years. Those facts indicate the relevance of studying the system of training Russian translators / interpreters in the PRC identifying the main problems of this system and finding ways to solve them.

\section{Methods}

The methodological basis of the study was works devoted to the problem of organizing the educational process at universities. The methods of identifying problem areas, generalizing experience, as well as a comparative analysis of the information obtained are used. The curricula of different universities, the information about the testing system in the PRC and the information about competitions and contests for translators / interpreters were selected as the material for the analysis.

\section{Results}

Since 2011 Chinese universities have opened the admission of master's students in specialties related to translation and / or interpretation from Russian into Chinese and vice versa. Until that time master's students specializing in Russian could study only in one specialty — "Russian language and literature". Today translators are trained at 16 universities, and interpreters at 26 universities. The term of study for the educational programme is 2 or 2.5 years. The aim of the training is to prepare highly qualified translators and interpreters who have good language competence and translation skills, a wide range of knowledge and are able to cope with high-level translation activities in various fields (Ifan', Hun, 2018). 
In this connection, the systems of testing and encouraging translators / interpreters are also being improved. Since 2006 China Accreditation Test for Translators and Interpreters (CATTI) in Russian has been launched. This examination, organized on behalf of The Ministry of Human Resources and Social Security of the People's Republic of China, is administered by the China Foreign Languages Publication and Distribution Administration. The purpose of the examination is to determine the level of professionalism of translators / interpreters. All people, regardless of age, education level, length of service and place of work or study, can apply for participation in the second and third level examinations. Only those who pass the second level examination are admitted to the first level examination. Examinations are held annually in seven languages. The requirements for those taking the examination at different levels are as follows:

- first-level diploma: the examinee demonstrates a rich store of knowledge in the field of science and culture, a high level of translation / interpretation quality from one language to another and vice versa, the ability to cope with translation / interpretation tasks in a fairly wide range of areas, and perform rather complex translations;

- second-level diploma: the examinee demonstrates a certain store of knowledge in the field of science and culture, a good level of translation / interpretation quality from one language to another and vice versa, the ability to cope with tasks in a certain area and perform translations of a certain complexity;

- third-level diploma: the examinee demonstrates a basic knowledge in the field of science and culture, the ability to translate from one language to another and vice versa, the ability to cope with ordinary translation / interpretation tasks (China Foreign Languages Bureau Translation Professional Qualification Evaluation Center, 2020).

Written and oral examinations are held separately for each language. In many organizations, when hiring translators / interpreters, a diploma of translator / interpreter qualifications is a prerequisite. Thus, a well-established system for checking the level of competence of translators / interpreters was formed.

In order to encourage highly qualified translation personnel and stimulate their further professional development, various competitions are held annually in China oriented at the knowledge of the Russian language or directly devoted to translation and interpretation. Among them, the most 
authoritative and large-scale ones are Han Suyin International Translation Contest, Yun Wang Cup All-China Multilingual Interpreting Competition and the All-Chinese Russian Language Competition. The information on the listed contests and competitions is presented in Table 1.

Table 1. A comparison of the three largest contests (competitions) in the Russian language and translation / interpretation in China

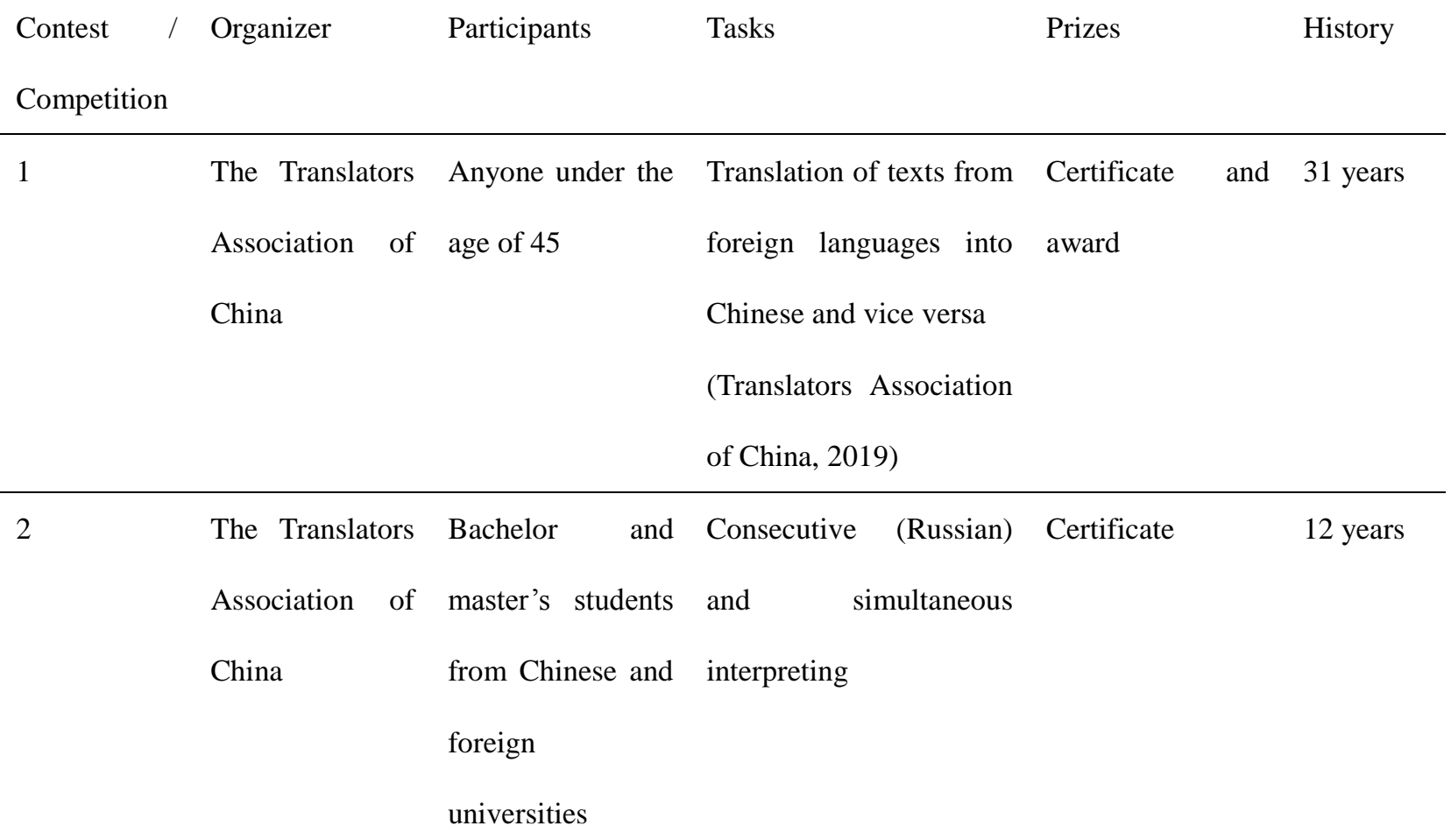

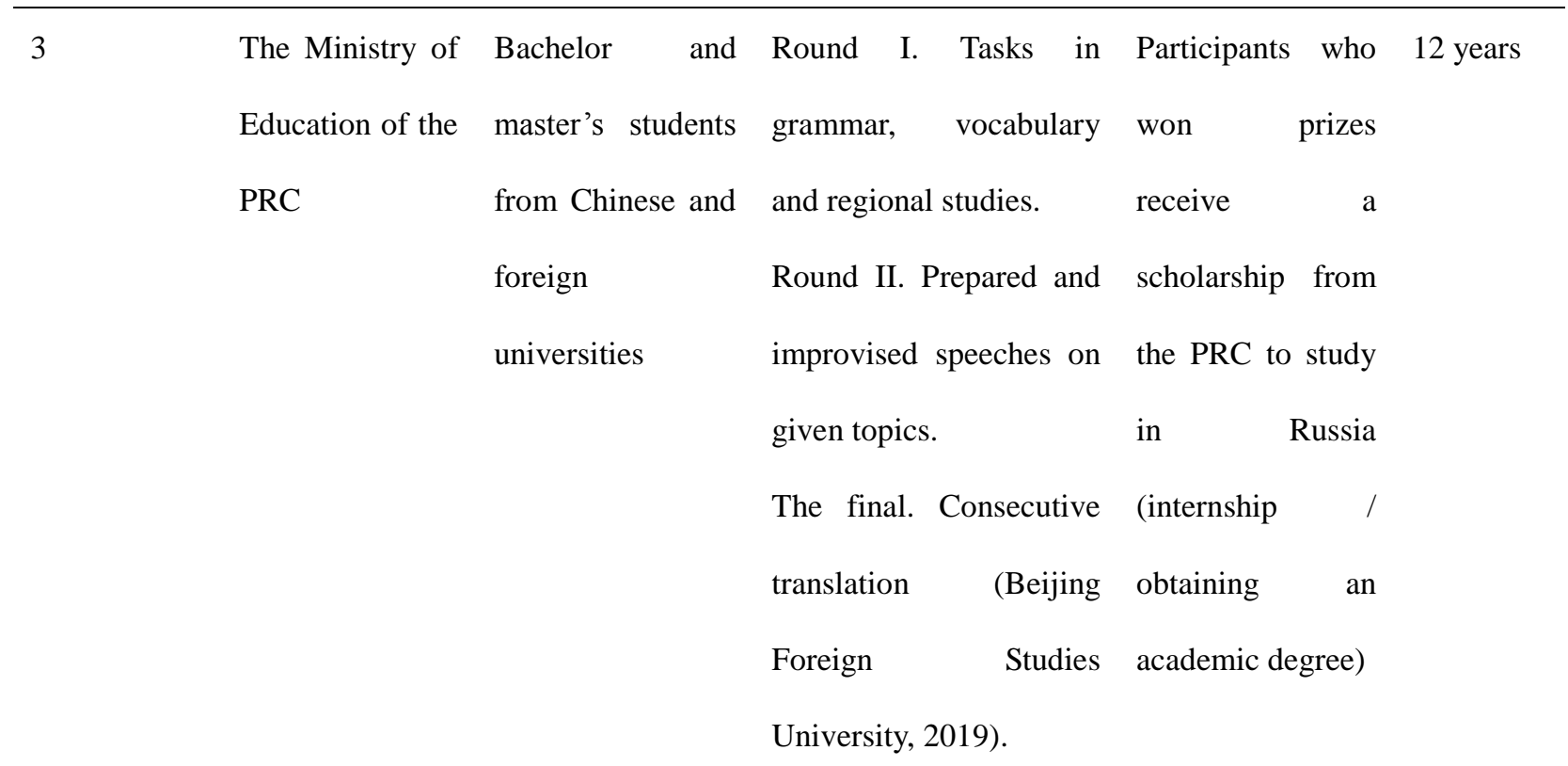

Despite the stability and expediency of the mechanism for training qualified Russian translators / interpreters in China, there are many problems that require strategic solutions. 
The first problem is a lack of specialized training for translators / interpreters oriented at the work in specific areas (Kaljakin, 2013). As an example, let us turn to the curricula of three prestigious universities in China that train linguists and translators / interpreters of the Russian language Beijing Foreign Studies University (BFSU), Shanghai International Studies University (SISU) and Heilongjiang International University (HLJU). The data on the studied disciplines are shown in Table 2.

Table 2. List of disciplines in the curricula of BFSU, SISU and HLJU

\begin{tabular}{ll} 
University & List of disciplines \\
\hline BFSU & Chinese language and culture; Written translation; Oral interpretation; Literary translation; Russian \\
& and Western theories of translation; Consecutive interpreting; Scientific translation; Trade and \\
& economic translation; Intercultural communication; Stylistics; Semantics; Language of the Russian \\
& media; Commercial translation; Political translation; Presentation and debate; English language. \\
\hline SISU & Consecutive interpreting from Russian into Chinese and vice versa; Consecutive interpreting from \\
English into Chinese and vice versa; Commercial translation; History of translation in China and \\
the West; Translation theory; International economics; Chinese culture; Development of world \\
civilization; Law basics; English language.
\end{tabular}

HLJU Chinese language and culture; Consecutive interpreting, Written translation; Translation theory; Stylistics; Russian language (advanced level); Simultaneous interpreting; Political translation; Scientific translation; Translation of news; Language of the Russian media; Cinematic translation; Intercultural communication; English language (Libo, 2017).

\section{Discussion}

After analyzing the curricula of the three universities it can be seen that the emphasis is on training Russian translators / interpreters in the political, trade, economic, scientific, cultural and media spheres. At the same time, in recent years China and Russia have also actively cooperated in other areas: military, space, energy and information. Working in these areas requires the translator / interpreter to have specialized background knowledge and the knowledge of terms in the two languages, which is a big problem without training focused on specific specialties. The market places high demands on translators / interpreters while the curricula of most universities do not meet these requirements (Yan, Zhehao, Lijuan, 2019). This situation is influenced by two factors. First, a lack of teaching staff who know both the Russian language and the specialized field. 
Secondly, there is a lack of study time to combine classes in the development of translation / interpretation skills and the study of a specialized field. In this situation, we see two solutions. Firstly, universities regularly invite professional translators / interpreters working in different subject areas to conduct classes in the form of optional subjects. In this case, students will have the opportunity to get acquainted with the peculiarities of the translator's / interpreter's work in the area in which the student is going to work in the future. Undoubtedly, it would be positive to introduce the practice of appointing two scientific advisors to students: a university teacher and a professional translator / interpreter. Professional translators / interpreters can provide students with the opportunity to develop translation / interpretation skills in a real-world setting, which will help students apply theoretical knowledge in practice, gain translation / interpretation experience and deal more easily with future work. Secondly, the training of translators / interpreters in a specific area related to the specifics of the university and / or the requirements of the regional market. In this connection, one can cite the example of The China University of Petroleum which trains translators / interpreters in the petroleum sector. The university itself is located in Shandong province where one of the largest oil fields in China is located (Daman, Xiuzhen, 2017). Working for oil companies based in Shandong is one of the best choices for graduates from this university. Working for oil companies based in Shandong is one of the best choices for graduates from this university.

The second problem requiring a strategic solution is a lack of pairing of bachelor's and master's degrees programmes. We mentioned above that in China specialized training of translators / interpreters begins only in the master's programme, while at the bachelor's level only individual translation / interpretation classes are held in the senior years (the average number of academic hours for translation / interpretation classes at Chinese universities does not exceed 4 hours per week (Linlin, 2013). Under such conditions it is difficult to prepare highly qualified translators / interpreters from students with relatively weak translation / interpretation skills in a short period of study in a master's program. To solve this problem it is advisable to introduce training in two directions in the senior years of a bachelor's programme - philology and translation, which corresponds to two specialties related to the Russian language in a master's programme.

The third problem is a shortage of international scientific exchange. Master's students specializing in translation / interpretation usually do not have the opportunity to undertake an internship in Russia due to the short study period and a lack of continuity in the curricula of Russian and Chinese 
universities, although international scientific exchange plays an important role in the training of translators / interpreters. In this regard, Heilongjiang International University has shown a good example. In 2018 Heilongjiang International University together with Moscow State University opened the Chinese-Russian Higher School of Translation. The first year of master's study takes place in China, and the second year in Russia. After graduation, master's students receive diplomas from two universities (Heilongjiang University, 2018). Unfortunately, such joint projects are unlikely to be carried out in every university, therefore, it seems to us that the following measures are justified to solve this problem: 1) to carry out short-term (monthly or half-year) student exchange programmes between Chinese and Russian universities; 2) to regularly invite Russian scholars in the field of translation / interpretation to give lectures and conduct seminars at Chinese universities; 3) to regularly hold international scientific and practical conferences on translation / interpretation in China where translators and interpreters from around the world can share their experience.

Finally, the fourth problem is a limited admission to participation in competitions / contests. In most competitions / contests for translation or interpretation, including translation / interpretation in the Chinese-Russian language pair, only university students can take part. This does not stimulate the continuous self-development of translators / interpreters who have already completed their studies. In this connection, it is proposed to hold more competitions / contests without restrictions for participants or with the division of competitors into two categories - university students and professional translators / interpreters.

\section{Conclusion}

Thus, as a result of the analysis of the system of training qualified Russian translators / interpreters in China, four main problems were discovered that affect the quality of translator / interpreter training: a lack of training translators / interpreters oriented at the work in specific special fields; a lack of connection between bachelor's and master's degrees programmes; a lack of international scientific exchange and a limited admission to participation in translation and interpretation competitions / contests. To solve these problems it is necessary to optimize the curricula of universities, strengthen the cooperation with Russian universities and improve the system of encouraging translators / interpreters. 


\section{Acknowledgements}

I would like to express my gratitude to my supervisor Maksim Sergeyevich Shishkov for his valuable comments during my research and writing this article.

\section{References}

Beijing Foreign Studies University. (2019). 2019 National College Russian Competition held in Beijing [EB/OL]. Retrieved from: https://ru.bfsu.edu.cn/info/1146/1497.htm

China Foreign Languages Bureau Translation Professional Qualification Evaluation Center. (2020). Introduction to the Basic Situation of the National Translation Professional Qualification Examination [EB/OL]. Retrieved from: http://www.catticenter.com/cattiksji/1394

Daman, S., Xiuzhen, S. (2017). Exploration and Practice of the Training Model of the Petroleum Specialized Master of Russian Translation (MTI) under the Background of "One Belt and One Road" - Taking the training of the Master of Russian Translation of China University of Petroleum (East China) as an example[J]. Course Education Research, 48, 218-219.

Heilongjiang University. (2018). Heilongjiang University-Moscow State University High School Opening Ceremony Held. Retrieved from: http://www.hlju.edu.cn/info/1043/4878.htm

Ifan', G., Hun, S. (2018). On the training of specialist translators / interpreters at MTI. Pedagogicheskoe obrazovanie v Rossii (in Russian), 4, 85-90.

Kaljakin, A.S. (2013). The professional training of a linguist, translator / interpreter in modern conditions, Rhema, 2, 103-109.

Libo, Y. (2017). A survey report on MTI Russian interpreting teaching in three universities in Harbin[D]. Inner Mongolia Normal University.

Linlin, L (2013). The Design of Russian Interpretation Courses in Chinese Universities[D]. Beijing International Studies University.

Translators Association of China. (2019). Announcement No. 1 of the 12th "AEON Cup" Multilingual National Interpretation Competition. Retrieved from: http://www.tac-online.org.cn/index.php? $\mathrm{m}=$ content $\& \mathrm{c}=$ index $\& \mathrm{a}=$ show $\&$ catid=395\&id=347 
Yan, Z., Zhehao, P., Lijuan, L. (2019). Russian Translator Training in the MTI Program in the Setting of The Belt and Road Initiative[J]. Foreign language research in Northeast Asia, 7(01), 87-91. 